\title{
Geotechnical Aspects of Storage Tank Foundation Types
}

\author{
Amin Moradi $^{1} *$, Amir Mahmoudzadeh ${ }^{2}$, Yahya Rahim Safavi $^{3}$ \\ ${ }^{1}$ Master of Technology in Civil Engineering Ph.D Scholar In Reserch Institute Of Shakhes Pajouh Esfahan, Iran \\ ${ }^{2}$ Master of Technology in Civil Engineering Head of Department \& Chancellor In Reserch Institute Of \\ Shakhes Pajouh Esfahan, Iran \\ ${ }^{3}$ Professor of Political geography
}

\begin{abstract}
Storage tanks are available in many shapes: vertical and horizontal cylindrical; open top and closed top; flat bottom, cone bottom, slope bottom and dish bottom. Large tanks tend to be vertical cylindrical, or to have rounded corners transition from vertical side wall to bottom profile, to easier withstand hydraulic hydrostatically induced pressure of contained liquid. Most container tanks for handling liquids during transportation are designed to handle varying degrees of pressure.
\end{abstract}

Keywords: pressure; tanks; shapes; flat bottom; cone bottom; hydraulic hydrostatically

How Tanks Are Welded:

\section{Introduction}

Four basic welding processes are used in fabricating steel tanks and pressure vessels. Each of the four processes (whether manual or automated) will repeatedly produce quality weldments. But they each have strengths and weaknesses. Prospective tank buyers should be aware of the different processes. In general, the best fabricators focus intensely on assuring outstanding fit-up. Many combine that dedication with the use of automatic weld processes which typically leads to high-quality welds.

\section{Leak Testing}

Once a tank is completely welded, the tank will be visually inspected and checked for leaks. Most cylindrical atmospheric tanks are tested at 5 psi. Tank openings are sealed, and compressed air is applied to the tank until the necessary test pressure is achieved. It is important to consider the volume of air applied to the tank when pressurizing. While the test pressure is not that great, the volume of air is significant and, in the event of an accident, can cause severe injury to nearby personnel. Fabricators are required to have a safety relief device on the tank to prevent overpressurization.

Once the test pressure is achieved, a soap solution is applied over the welds to identify leaks. Bubbles are created when air leaks through the weld and are readily identified by the tester. Leaks are then repaired before the welds are retested to ensure the tank's integrity.Testing of tanks should be performed in a well-lit area. All gages, relief valves, and testing equipment should be in good working condition. Soap testing solution should be protected from contaminants. The tank welds should be free of slag, spatter, or foreign materials that prohibit testing.Most double-wall tanks will, in addition to the bubble test, have a vacuum applied to the interstitial space. Comparing a vacuum to the bubble test is like comparing apples to oranges. The vacuum is much more sensitive to leaks than the bubble test, and is most effective at proving simultaneously that both the primary and secondary tanks are tight.

\section{Surface Preparation}

Tanks that have coatings or laminates applied directly to the exterior steel shell should be prepared by abrasive blasting, which will remove mill scale and roughen the surface to improve adhesion of the paint or coating. Typically the resultant profile left on the steel is between 1.5 and 3.5 mils deep. The blast medium used is often coal slag, silica sand, or recycled grit. The profile depth depends upon the size, type, and hardness of the blast media; particle velocity; angle of impact; surface hardness; and maintenance of the working mixture.

The coal slag and grit tend to give a deeper profile versus the sand. However, the sand tends to remove mill scale easier from the surface. Under most circumstances shot or wet blast should not be used for surface preparation on steel tanks. Prior to coating, the tank should be free of abrasives, oil, grease, or other contaminants. Most fabricators will apply the coating to the tank as soon as possible after blast. The longer a blasted, uncoated tank is exposed to the environment, the greater the chance that rust-back will occur, especially in locations subject to high relative humidity. Should rust-back occur, the entire tank should be reblasted.

\section{Coatings}

There are hundreds of different coatings on the market today designed to meet very specific applications. Years ago, many tank suppliers used a coal-tar coating. The coal tar was an excellent coating, and was relatively 
trouble free. The problem with the coal tar was that it took roughly 24 hours to cure before you could move the tank. The long cure time didn't help tank manufacturers as it created a logjam at the coating application stage.Coating manufacturers eventually introduced a polyurethane product that provided the necessary corrosion protection and reduced the cure time significantly enabling the fabricator to move the tank within minutes on a hot day, or just a few hours in cooler weather. With the reduction in curing time most fabricators switched from the coal tar to the polyurethane coatings.

While the polyurethane is a very good coating, it is much more susceptible to application errors or defects. Since the coating is a two-part system, the coating actually mixes at or near the spray nozzle. The ratio by volume of a coating manufacturer's proprietary Part A to Part B in the mixture is critical. Many coating defects are directly attributed to the mixing ratio and may cause the urethane to blister if the ratio is off. Many jacketed and composite tanks use an isophthalic fiberglass-reinforced polyester (FRP) laminate to provide a corrosion barrier. The fiberglass laminate is an excellent coating for corrosion protection. The application of the laminate requires a skilled operator and well-maintained equipment. The operator must ensure that the correct ratio of glass to resin is maintained at all times. A skilled operator will be able to work around attachments and manways and maintain a holiday-free coating. Most fiberglass-clad tanks require a holiday test a high-voltage examination of the external tank surface that will discover any exposed metal.

All fabricators will use some kind of inhibitor to protect the tank from ultraviolet light while the tank is in storage. Many fabricators will use a color additive in the final phase of coating for added UV protection. Prior to adding the gel coat color, fabricators can visually inspect the coating for flaws. Many jacketed tank technologies also use FRP as a corrosion barrier. Because the jacketed tank design calls for the FRP to serve as an outer tank, there is always some spacer material between the steel tank and the FRP shell. This eliminates most of the need to blast the tank. Blasting only occurs where the laminate directly makes contact with the steel. This is usually around the fittings and manway.

\section{Inspection}

The best time to inspect a UL 58 or UL 142 steel tank is just prior to coating application. Once coated, evaluation of the fabrication and welding is often difficult, if not impossible. By inspecting prior to coating, you have the opportunity to examine all weld profiles to ensure they meet specification. This also enables the removal of excess spatter. Prior to applying the corrosion barrier, it is important to ensure that no sharp edges are present to inhibit the coating process.

Once the coating has been applied, the inspector should determine if the urethane, FRP, or coal-tar epoxy has the minimum dry-film thickness required by the specification on the entire tank. Inspectors can measure dry-film thickness in a number of tank shell locations with a gage. The coating should be free of sags, runs, blisters, or other surface defects. Composite tanks require a 10,000 to $35,000 \mathrm{~V}$ holiday test to ensure that the laminate completely protects the steel from corrosive elements. Check with local officials on requirements. It is recommended that the ground wire lead from the holiday tester be connected directly to the tank for maximum detection of coating defects or flaws.

\section{Internal Pressures:}

Fabrication standards for USTs call for building the tanks to atmospheric pressures, capable of withstanding integrity testing of up to 5 psi. The internal pressures on USTs that hold flammable and combustible liquids are seldom a concern because tank burial virtually assures a lack of extreme fluctuations in product temperatures. Fabricators, however, face an entirely different situation with ASTs loaded with fuel and exposed to sunlight in hot weather, or potentially at risk to catch fire at the tank site. Fire codes require the addition of a fitting for an emergency relief vent to prevent AST fueling tanks from building up explosive internal pressures. Internal pressures also affect the fabrication of vertical ASTs. Because liquids exert greater pressure at the bottom of a container, vertical aboveground tanks employ thicker-gage steel at the bottom of the cylinder than the top. Vertical ASTs also are tested to hold 2.5 psi vs. 5 psi for horizontal tanks.

\section{External Pressures}

Soils and UST backfill materials - shift periodically. Earthquakes and highwater tables created by localized flooding are probably the most dramatic examples of natural events that can place undue pressure on tanks. But years of experience have shown fabricators that special burial conditions can also influence the selection of materials for tank construction. For example, if the tank is going to be buried deeper than $5 \mathrm{ft}$ below grade, additional steel thickness may be required to assure structural integrity.On rare occasions, deep tank burials take place in areas where high groundwater levels exist. There are documented instances when marginal steel thicknesses have been used in the production of the tank, which deformed the tank bottoms in essence, crimping the shell upwards. When fabricators are apprised of unusual conditions at the tank site, a UST can be stiffened through thicker walls, or by incorporating steel structural elements. For example, all nonmetallic USTs use 
reinforcing ribs to obtain the necessary integrity to prevent buckling. When coupled with proper backfill and placement, the FRP tank design will minimize the risk of cracking.

\section{Corrosion Protection}

Underground storage tanks require corrosion protection to comply with the U.S. Environmental Protection Agency's technical requirements for USTs. On steel tanks, fabricators provide corrosion protection to the primary tank through dielectric coatings, cathodic protection, secondary containment or sometimes a combination of methods (e.g., fiberglass-reinforced plastic coating supplemented by anodes).

\section{Weld Joints:}

Usually the tank manufacturer will determine the weld joint design(s) to be used in fabrication. The engineer or specifier may want to inquire on the type of joints typically employed by the manufacturer, especially on tanks that will have a lining, such as a vessel used for jet fuel storage. Some weld joints are better than others for internally lined tanks.

For example Figure (1) illustrates a schematic arrangement of each group of tanks in reclamation area and relevant dimensions.

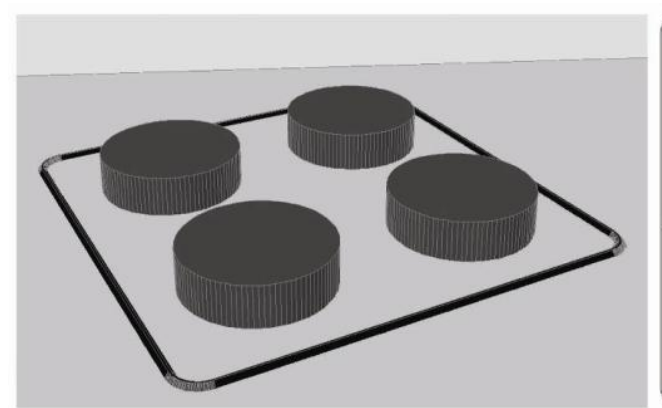

Figure (1)

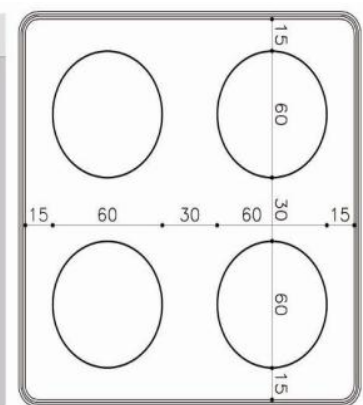

$\overrightarrow{4}$

\section{Different Alternatives For Tank Foundations.}

In general, applicable foundations for storage tanks can be divided into five categories. There is no unique answer for best tank foundation to use in all situations. Each case should be evaluated on the basis of its individual conditions.

\subsection{Earth Foundation:}

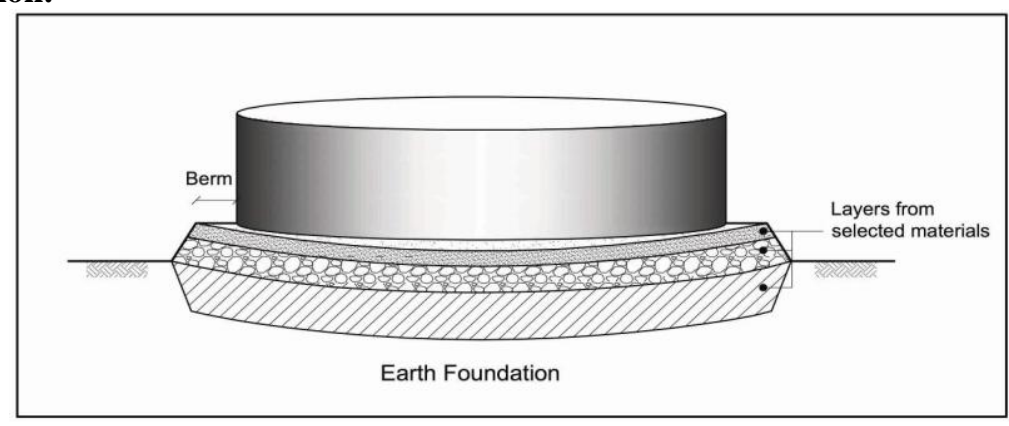

Figure 2- Example of an earth foundation for tank

Earth foundations can be the most economic foundation for tanks and also they have advantage of a simple construction procedure. Although, because there is no support under tank shell, settlement might become critical in that area and led to a non uniform settlement which can cause bottom damages.Also heavy loads applied by shell and roof weight can cause stress concentration under the edges of the tanks and may be led to local failure under shell.In fact, fluid weight in tank produce a uniform surcharge on the tank support. Figure (3left) shows the uniform surcharge on the tank support due to fluid weight. But in real, the fluid inside the tank is contained by tank shell which is constructed from steel. Because of the considerable difference between specific gravity of tank contents and tank shell itself large amounts of stress would be produced under tank shell. Figure (3-right) shows a schematic sketch of such a difference between stress values under the tank bottom and tank shell. It should be mentioned that because of load transfer system in fixed roof tanks, the mentioned stress difference is even higher in fixed roof tanks rather than floating roof tanks. 


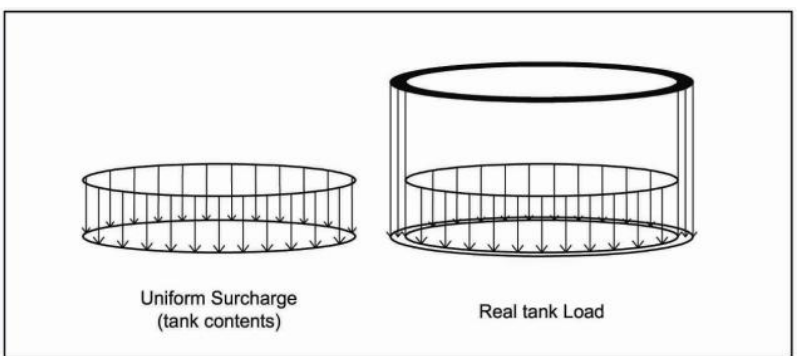

Figure 3- Comparison between stress caused by fluid weight and shell weight

A uniform load, such as those caused by tank contents, can cause a predictable smooth settlement under the tank. Figure (4) shows a schematic sketch of the settlement caused by a uniform surcharge. In contrast to the uniform surcharge, the level of stresses which could be produced under the tank shell can change the settlement regime under the tank shell. Figure (5) shows settlement caused by real tank loading on an earth foundation.

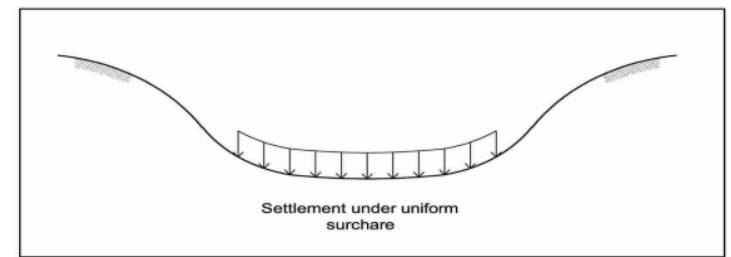

Figure 4- Settlement of an earth foundation due to the uniform loading

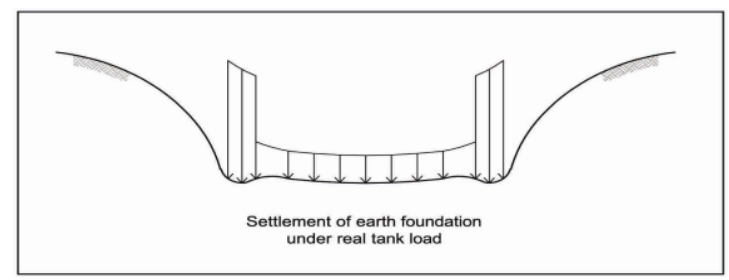

Figure 5- Settlement of an earth foundation due to the real tank loading

\subsection{Earth Foundation with Concrete Ringwall}

A very commonly used type of tank foundation is an earth foundation surrounding by a concrete ring wall. In this type a concrete ring foundation is considered under the shell to support the heavy loads imposed by the shell (Figure 6). Ring walls can be highly recommended in presence of large tanks, tanks with heavy or tall shells or self supported roofs which apply a substantial load on the foundation under the shell.

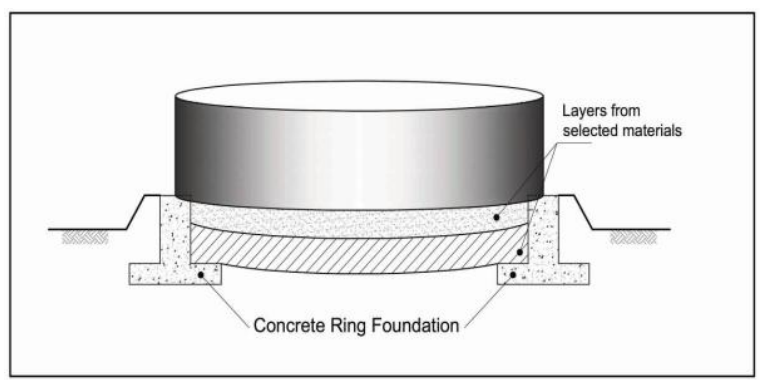

Figure 6- Example of tank foundation with concrete ring wall

There are several advantages in the use of concrete ring wall in tank foundations:

a) It provides an excellent foundation for tank shell and causes better distribution of the concentrated load of the shell to produce a more uniform soil loading under the tank.

b) It provides a level, solid starting plane for construction of the shell.

c) It provides a better means of leveling the tank grades, and it is capable of preserving its contour during construction.

d) It retains the fill under the tank bottom and prevents loss of material as a result of erosion.

e) It eliminates washing and weathering of berms.

f) It prevents the surface water running into the grade. 
g) It prevents the lateral movement of the filling material under the tank bottom.

h) It results in a neat appearance.

In cases of using ring wall foundation, as a result of more uniform stress distribution on soil, settlement variation can be more smooth under the tank. In fact, using concrete ringwall would increase the rigidity of tank support beneath the sell (Figure 7-a). Due to this rigidity and also increased stresses beneath the tank shell, tank support would be settled smoother than the case of using earth foundation (Figure7-b). In addition, concrete ringwalls has another advantage in confining the filling materials beneath the bottom shell and make an increase in their bearing.

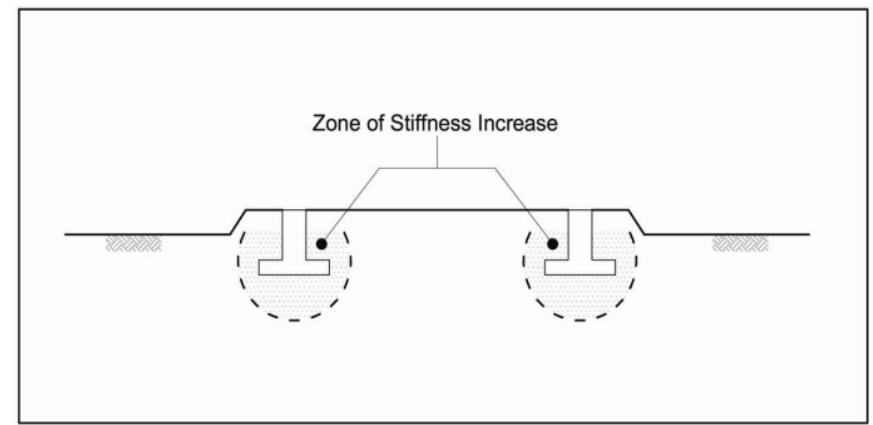

Figure 7-a- Increase of the stiffness around the concrete ring wall

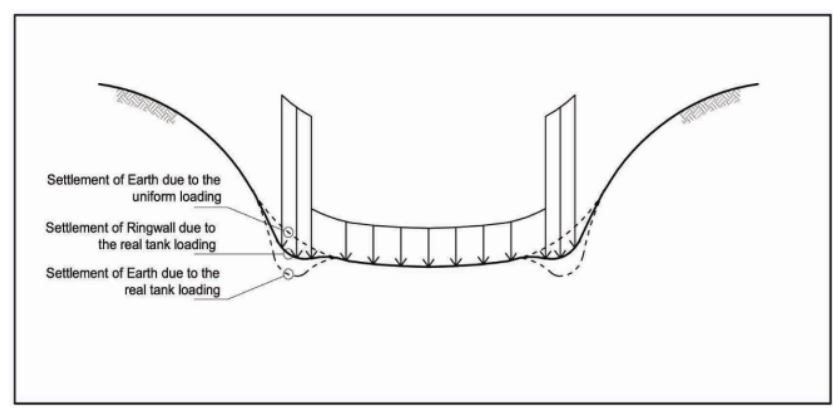

Figure 7-b- Smoothened settlement beneath the concrete ring wall

On the other side, the most important concern of ring walls application is about the settlement of the filling soil just beside the ringwall. Because the stiffness of the base is suddenly decreases when moving from concrete ringwall to the center of the foundation, settlement may be immediately increased just beside the ringwall. Although the compaction of the gravel pad has some difficulties, but complete compaction of filling adjacent to the ring wall with handy tampers can minimize immediate change of settlement.

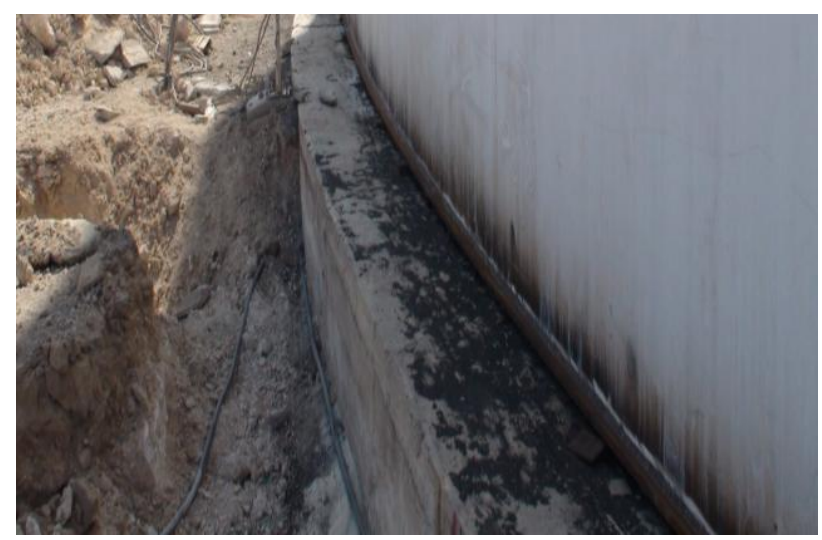

Figure 8- Using concrete ringwall

\subsection{Earth Foundation with Crushed Stone Or Gravel Ringwall:}

As an alternative to the concrete ringwall noted in last section, a crushed stone ringwall can be applied with an earth foundation (Figure 9). A crushed ring wall is replaced under the shell and the area under the tank bottom shall be filled with thoroughly compacted fill of fine gravel, coarse sand or other stable material. 


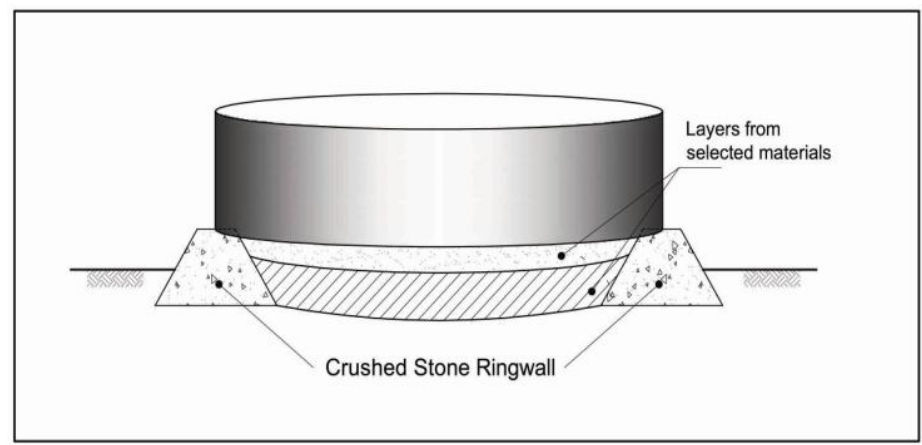

Figure 9- Example of tank foundation with concrete ring wall

As concrete ringwalls, the first role of crushed stone is providing adequate support for high loads imposed by shell. Other advantages of crushed stone ringwalls are as follows:

a) It provides better distribution of the concentrated load of the shell to produce a more nearly uniform soil loading under the tank.

b) It provides a means of leveling the tank grade, and it is capable of preserving its contour during construction.

c) It retains the fill under the tank bottom prevents loss of material as a result of erosion.

d) It can more smoothly accommodate differential settlement because of its flexibility.

There are some disadvantages in the use of crushed stone ringwall. First of all is that it is more difficult to construct it to close tolerances and achieve a flat, level plane for construction of the tank shell. Although the mentioned advantages of crushed stone ringwalls, careful selection of design details is necessary to ensure satisfactory performance. Especially drainage system required to be thought and constructed carefully. In addition, in this project availability and expensive cost of crushed stone materials are other problems of this foundation.

\subsection{Reinforced Concrete Slab Foundation:}

Reinforced concrete slab foundation is a common approach for small tanks but not for large storage tanks. They can be used when the soil bearing loads must be distributed over an area larger than the tank area or when tank owner insists on a rigid uniform foundation. Figure (10)

shows a typical sketch of reinforced concrete slab foundation.

In large tanks, reinforced concrete slab could be led to very large added cost. The first cause of added cost is that the area is too large and the volume of concrete becomes great. In addition, relatively small differences in soil settlement under the slab, can cause initiating and developing cracks in the slab, so the concrete slab should have a considerable thickness for large tanks. So in usual cases no one recommend reinforced concrete slab as a choice for large storage tanks.

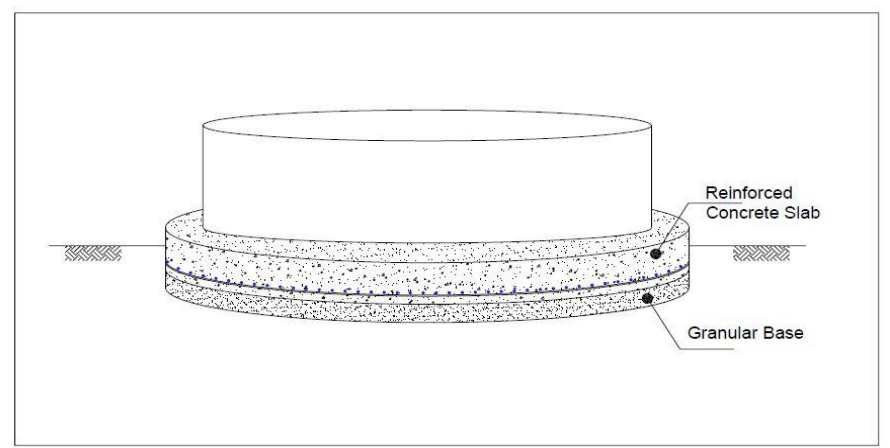

Figure 10- A typical sketch of tank foundation with reinforced concrete slab

\subsection{Piled Foundation:}

In some special cases that tanks or equipments are so sensitive to settlement or in cases where subsurface condition is very poor, piled foundation is the choice. In this kind of foundation, piles made of concrete or other suitable materials are replaced under the concrete slab beneath the tank.

Figure (11) shows a typical sketch of pile foundation package (piles plus pile cap) as a tank support system. 


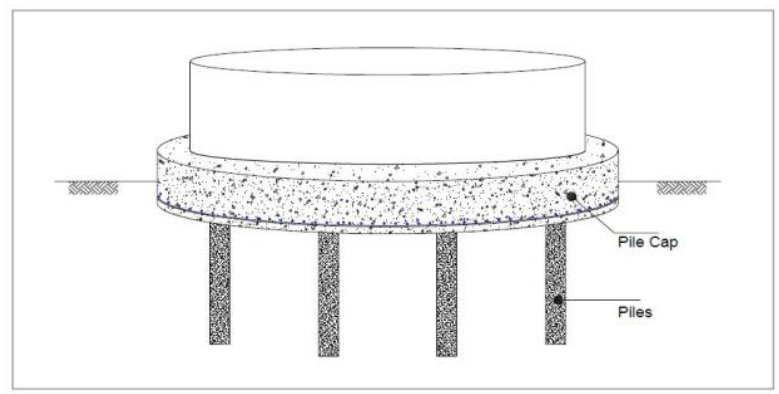

Figure 11- A typical sketch of tank foundation with pile system (piles + pile cap).

Use of piled foundation, economically is rejected for large tanks. Owners prefer to change the site location rather than construction of a piled foundation. But where the condition is such that the location can not be changed and none of the simpler foundation types are adoptable, piled foundations or other special types will require individual consideration for each case.

\section{Conclution :}

\section{Criteria For Tank Foundation Type Selection:}

There are many factors that affect selecting the proper type of tank foundation.

\section{Bearing Capacity:}

The primary factor is the bearing power of the soil. Especially in tanks with large height and small areas which imposed high loads on the soil, bearing capacity may become critical. As a general approach limiting tank height can lead to saving foundation expenses. So a large tank with lower height and larger area is preferred to a large tank with larger height and lower area.

\section{Settlement:}

Second important design criteria of tank foundation is allowable settlement. The allowable settlement is highly dependent on tank details and related equipments. In addition dimensions of the tank can affect the maximum allowable settlement. On the other hand in large tanks magnitude of total settlement is not very sensitive to the type of foundation. Because the area of loading is very large and effective depth of loading is too much. But the type of foundation shall have great effects on smoothing and limiting differential settlements. Since different settlement in parts of tank can cause excessive stress in shell and bottom It is very important to select a foundation which can minimize the differential settlement of tank.

\section{Cost Effectiveness:}

After safety the major criteria for selection of tank foundation is the cost. Every owners like to have a safe design with the least expenses. In large tanks of this project, foundation cost is considerable. So at first availability and cost of construction materials should be carefully watched. Then cost of construction and possibility of construction methods should be evaluated based on the local conditions and equipments.

\section{Construction Considerations}

Construction considerations should always be indicated in design procedure. Foundations which are easy to grade and level are preferred to others. Since the compacted base is very important in preventing differential settlement, thorough compaction of filling should be easily satisfied in construction procedure.

\section{References}

[1] HANDBOOK OF STORAGE TANK SYSTEMS edited by Wayne B. Geyer Steel Tank InstituteLake Zurich, Illinois

[2] PI Standard 650 - Welded Steel Tanks for Oil Storage, 1993

[3] D Yergin. The Prize. New York: Simon \& Schuster, 1991, p 27-28.

[4] Steel Tank Institute, sti-P3® Specification and Manual for External Corrosion Protection of Underground Steel Storage Tanks. Lake Zurich, IL, STI-P3-97 specification, 1997.

[5] Steel Tank Institute. UL Issues 1st Proposed Edition of New UL 2244 Systems Listing. Tank Talk XIII(3), 1998.

[6] 1. RL Sanderson. Codes and Code Administration: An Introduction to Building Regulations in the United States. Chicago: Building Officials Conference of America, 1969.

[7] Steel Tank Institute. [Background posted on the World Wide Web.] Lake Zurich, IL. Retrieved October 24, 1998, from the World Wide

[8] DIN 18800-4, Stahlbauten, Schalenbeulen, 1994

[9] Hornung, U. and Saal, H. - Stresses in Unanchored Tank Shells due to Settlement of the Tank Foundation

[10] Carrying Capacity of Steel Shell Structures, Proc. ECCS, Brno(Czech), 1997

[11] Hornung, U. and Saal, H. - Stresses in Tank Shells due to Settlement taking into account local uplift

[12] Advances in Steel Structures, Proc. ICASS'06, Hong Kong , 1996 